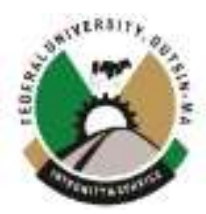

\title{
IN VITRO SENSITIVITY PROFILES OF ENTERIC BACTERIA ASSOCIATED WITH DIARRHEIC PATIENTS WITHIN KATSINA METROPOLIS, KATSINA STATE, NIGERIA
}

\author{
${ }^{* 1}$ Odewade, J. O., ${ }^{2}$ Fasogbon, A. O. and ${ }^{1}$ Onyekachi, F. S. \\ ${ }^{1}$ Department of Microbiology, Federal University Dutsin-Ma, Katsina State, Nigeria. \\ ${ }^{2}$ Department of Microbiology, Bayero University, Kano, Kano State, Nigeria. \\ *Corresponding Authors’ Email: odewadejoseph@yahoo.com
}

\begin{abstract}
Diarrheal disease is a leading cause of mortality and morbidity across the globe. However, there is little information on the prevalence and antimicrobial sensitivity patterns of microbes associated with diarrheic patients within Katsina Metropolis, Nigeria, hence, the need for this study. Forty (40) stool samples were collected from Federal Medical Center, Katsina, Katsina State, Nigeria. Isolation and identification of the bacteria from the stool samples were carried out using standard microbiological techniques. Antibiotics sensitivity testing was carried out on all the bacterial isolates using disk diffusion method. Seventeen (17) bacterial isolates were isolated from three different genera. These include: Escherichia coli (58.82\%), Salmonella typhi $(29.41 \%)$ and Shigella dysenteriae (11.77\%). The results of antibiotics sensitivity test showed a high $(100 \%)$ resistance to amoxicillin, $70.59 \%$ resistance to streptomycin, $41.18 \%$ resistance to nalixidic acid and least (17.65\%) resistance to imipenem. Multi drug resistant Escherichia coli and Shigella species were also detected. The high level of antibiotic resistance among bacterial isolates obtained from stool samples of diarrheic patients is quite alarming and requires urgent public health attention. Hence, further studies are required for the molecular detection of the resistant genes in these bacteria.
\end{abstract}

Keywords: Enteric bacteria, antibiotic sensitivity testing, antibiotic resistant bacteria, multi-drug resistant bacteria, diarrheic patient

\section{INTRODUCTION}

Diarrhea is defined as a disease condition characterized with the passage of three or more loose stools per day or more frequent passage than is normal for an healthy individual (WHO, 2012). World Health Organization (WHO) reported increased episodes of diarrhoea every year in low income country (WHO, 2011). In low-income countries, children under three years old experience on average, three episodes of diarrhea every year (WHO, 2011). Each episode deprives the child of the nutrition necessary for growth. As a result, diarrhea is a major cause of malnutrition, and malnourished children are more likely to fall ill from diarrhea (Kahali et al., 2004).

Diarrhea is spread through contaminated food or drinkingwater, or from person-to-person as a result of poor hygiene (Mensah et al., 2002). It is usually a symptom of an infection in the intestinal tract, which can be caused by a variety of bacterial, viral and parasitic organisms (Kaler, 2008). Infective bacterial diarrhea is a global health problem (Kolader et al., 2013). Severe infective bacterial diarrhea can cause brain damage and death. Many bacterial species have been implicated as a cause of infective diarrhea such as Salmonella spp, Campylobacter spp, Shigella spp, Vibrio spp, Yersinia spp and Escherichia coli (DuPont, 2014). Salmonellosis, Shigellosis, Yersiniosis and Campylobacter infections cause potentially serious diarrheal disease (Center for Disease Control and Prevention, 2009).

Environmental factors also influence the distribution, diversity, and incidence of the disease. Diarrhea as other human specific illness is linked to change of season, local weather pattern and other environmental factors. These factors facilitate the spread of diseases since they have interaction between disease agents and vectors, which have particular environments that are optimal for growth, survival as well as transport (Kosek et al., 2003). Nigeria like other parts of the world has experienced seasonal epidemics of acute diarrhea such as cholera and dysentery usually during the rainy seasons, when many cases are reported in both primary health centers and central hospitals. In Nigeria, diarrhea (including dysentery and cholera) is the leading cause of morbidity and mortality in people. There is a limited data regard to prevalence of enteric pathogenic bacteria and many surveys conducted focused only on epidemiology of cholera and few diarrhea cases (Ajoke et al., 2012). It was estimated that during the next 20-30 years, diarrhea along with other infectious diseases will remain a cause of global health concern (Meyrowitsch and Bygbjerg, 2007). Antimicrobial chemotherapy can shorten both the bacterial excretion and duration of illness (Mandomando et al., 2007). However, this will depend on where the patient/guardian chooses to seek healthcare and also the individual's perception of the disease. Apart from cost of treatment, diarrheal pathogens are becoming increasingly resistant to antimicrobial agents. Therefore, this study aims at investigating in vitro sensitivity profiles of enteric bacteria associated with diarrheic patients within Katsina Metropolis, Katsina State, Nigeria. 


\section{MATERIALS AND METHODS}

\section{Ethical Approval}

Ethical Approval was obtained from Federal Ministry of Health Research Ethical Committee, Federal Medical Center, Katsina, Katsina State, Nigeria with Approval number (FMCNHREC/22/08/2019). Informed consent was also obtained from the patients sampled.

\section{Sample collections}

Forty stool samples were collected from diarrheic patients using clean, dry and leak proof sterile bottles at Federal Medical Center, Katsina, Nigeria between August and October, 2019. The samples were transported immediately on ice packed to Microbiology Laboratory, Department of Microbiology, Federal University, Dutsin-Ma, Dutsin-Ma, Katsina State, Nigeria.

\section{Isolation of bacterial isolates}

Exactly, $1 \mathrm{ml}$ of stool samples from diarrheic patients was inoculated into $5 \mathrm{ml}$ of Selenite $\mathrm{F}$ broth and incubated at $37^{\circ} \mathrm{C}$ for 24 hours, followed by streaking on MacConkey (MA) agar, Salmonella-Shigella (SS) agar, Xylose Lysine Deoxycholate (XLD) agar and Eosin Methylene Blue (EMB) agar plates. The plates were incubated at $37^{\circ} \mathrm{C}$ for 24 hours. The plates were then sub-cultured by re-streaking on MacConkey agar, SalmonellaShigella agar, Xylose Lysine Deoxycholate agar and Eosin Methylene Blue agar plates. Afterwards, the plates were observed for colony formation after 24 hours of incubation. Growth of Salmonella species, Shigella species and Escherichia coli were detected by their typical colony characteristics on SSA, XLD and EMB Agar.

\section{Identification of bacterial Isolates}

Identification of bacteria isolates were done based on Gramstaining, colony morphology and biochemical tests. Biochemical characterization were carried out as described by Cheesbrough. (2006). These include Voges Proskaeur (VP) test, Urease, Oxidase test, Citrate test, Methyl red test, Indole test, Sugar fermentation (Glucose, Sucrose, Lactose and Mannitol) and Catalase test. The bacterial isolates were further cultured on Triple Sugar Iron (TSI) agar medium by stabbing the butt and streaking the slant and then incubated at $37^{\circ} \mathrm{C}$ for 24 hours to determine their glucose and lactose fermentation abilities and production of hydrogen sulfide. The Triple Sugar Iron agar (TSIA) tubes were examined for specific growth and appearance of Escherichia coli, Salmonella species and Shigella species.

\section{Motility test}

The test was carried out to determine whether the isolates were motile or not, motility medium were inoculated with a straight inoculating needle through a single stab about 1-2 $\mathrm{cm}$ down into the medium and incubated at $37^{\circ} \mathrm{C}$ for 24 hours. Based on their appearance on motility medium, the isolates were categorized as motile and non-motile.

\section{Maintenance of pure culture}

The bacterial isolates were purified by repeated sub-culturing onto nutrient agar medium. The pure cultures were inoculated on nutrient agar slants and incubated at $37^{\circ} \mathrm{C}$ for 24 hours and then stored in the refrigerator at $4^{\circ} \mathrm{C}$ for further analysis.

\section{Standardization of inoculum}

Overnight culture of pure and discrete colonies of each isolate was transferred into each sterile test tube containing $5 \mathrm{ml}$ sterile nutrient broth and standardized to $0.5 \mathrm{McFarland}$ standard (Ikram-ul-Haq and Mukhtar, 2016).

\section{Antibiotics sensitivity testing}

The antibiotic susceptibility testing was carried out using disc diffusion method (Clinical and Laboratory Standards Institute, 2019). Susceptibility testing was carried out on Mueller Hinton Agar (MHA) and sterilized by autoclaving at $121^{\circ} \mathrm{C}$ for 15 minutes before dispensing into sterile petri dishes. The plates were inoculated with standardized inoculums $(0.5$ McFarland standard) by means of sterile cotton swab which was used to introduce the organisms on entire agar surface. The antibiotics discs were aseptically applied to the surface of the agar plates with the aid of sterile forceps and then incubated in an inverted position at $37^{\circ} \mathrm{C}$ for 24 hours. After incubation, each zone of inhibition was measured to the nearest $\mathrm{mm}$ and interpreted by comparing with CLSI. (2019). The following standard antibiotic discs were used for the study; ciprofloxacin $(5 \mu \mathrm{g})$, gentamicin $(10 \mu \mathrm{g})$, ofloxacin $(5 \mu \mathrm{g})$, nalixidic acid $(30 \mu \mathrm{g})$, amoxicillin $(30 \mu \mathrm{g})$, streptomycin $(10 \mu \mathrm{g})$, chloramphenicol $(30 \mu \mathrm{g})$, tetracycline $(30 \mu \mathrm{g})$ and imipenem $(10 \mu \mathrm{g})$. The bacterial isolates that were resistant to three or more classes of antibiotics were classified as multi-drug resistant bacteria.

\section{RESULTS}

A total of forty stool samples were collected from diarrheic patients from Federal Medical Center, Katsina, Katsina state, Nigeria. Seventeen bacteria isolates belonging to three genera were recovered from the stool samples and identified as Escherichia coli, Salmonella spp and Shigella spp based on their gram reaction and biochemical characteristics.

The percentage prevalence for isolated and identified bacteria were shown in Table 1. Escherichia coli was the dominant organism with the percentage prevalence of $58.82 \%$ followed by Salmonella spp with $29.41 \%$ while Shigella spp was the least prevalent with $11.77 \%$.

Table 1: Prevalence of enteric bacteria from stool samples

\begin{tabular}{lcc}
\hline Bacteria & Number of Isolates & \% Prevalence \\
\hline Escherichia coli & 10 & 58.82 \\
Salmonella spp & 5 & 29.41 \\
Shigella spp & 2 & 11.77 \\
\hline Total & $\mathbf{1 7}$ & $\mathbf{1 0 0}$ \\
\end{tabular}


The bacterial isolates were mostly 17(100\%) resistant to amoxicillin (Table 2). However, Escherichia coli and Shigella species were more resistant to amoxicillin and streptomycin than nalixidic acid. The bacterial isolates were least resistant to imipenem $3(17.65 \%)$.

Table 2: Percentage resistance of bacteria isolated from stool samples

$$
\text { No (\%) of bacteria resistant to: }
$$

\begin{tabular}{|c|c|c|c|c|c|c|c|c|c|c|}
\hline Bacteria & $\begin{array}{l}\text { Number } \\
\text { of } \\
\text { bacteria } \\
(\%)\end{array}$ & CPX & GEN & NA & AMX & TET & $\mathbf{S}$ & $\mathbf{C H}$ & OFL & IMP \\
\hline $\begin{array}{l}\text { Escherichia } \\
\text { coli }\end{array}$ & $10(58.82)$ & 0 & 0 & $6(60)$ & $10(100)$ & 0 & $10(100)$ & 0 & 0 & $1(10)$ \\
\hline $\begin{array}{l}\text { Salmonella } \\
\text { Spp }\end{array}$ & $5(29.41)$ & 0 & 0 & 0 & $5(100)$ & 0 & 0 & 0 & 0 & $2(40)$ \\
\hline Shigella spp & $2(11.77)$ & 0 & 0 & $1(50)$ & $2(100)$ & 0 & $2(100)$ & 0 & 0 & 0 \\
\hline Total & 17(100) & $\overline{\mathbf{0}}$ & $\mathbf{0}$ & $7(41.18)$ & 17(100) & $\mathbf{0}$ & $12(70.59)$ & $\mathbf{0}$ & $\mathbf{0}$ & $3(17.6$ \\
\hline
\end{tabular}

Key: CPX=Ciprofloxacin, GEN=Gentamicin, OFL=Ofloxacin, NA=Nalixidic acid, AMC= Amoxicillin, S=Streptomycin, $\mathrm{CH}=$ Chloramphenicol, TET $=$ Tetracycline, IMP=Imipenem

Multi-drug resistance was observed among Escherichia coli and Shigella species as shown in Table 3. The resistant phenotypes of these bacteria revealed that the most prevalent multidrug resistant phenotype is found among Escherichia coli with $71.42 \%$ occurrence while the least prevalent multidrug resistant phenotype is found among Shigella species with $14.29 \%$ occurrence.

Table 3: Antibiotic resistant phenotypes of multi-drug resistant bacteria isolated from stool samples

\begin{tabular}{llll}
\hline Bacteria & No of antibiotics & $\begin{array}{l}\text { Multiple antibiotic } \\
\text { resistance pattern }\end{array}$ & No. of MDR isolates (\%) \\
\hline Escherichia coli & 4 & NA-AMC-S-IMP & $1(14.29)$ \\
& 3 & NA-AMC-S & $5(71.42)$ \\
Shigella species & 3 & NA-AMC-S & $1(14.29)$ \\
\hline
\end{tabular}

Key: NA=Nalixidic acid, AMC= Amoxicillin, S=Streptomycin, IMP=Imipenem

\section{DISCUSSION}

In Nigeria, and many developing countries, diarrhea caused by enteric bacterial pathogens especially Escherichia coli, Salmonella typhi and Shigella dysenteriae remains one of the major causes of morbidity and mortality among infants and young children (Ajoke et al., 2012) However, the situation in Nigeria still calls for more concern; this is because the incidence of diarrhea is still high in the country (Ajoke et al., 2012).

In this study, forty (40) stool samples were obtained from diarrheic patients attending Federal Medical Center, Katsina, Nigeria. Seventeen (17) bacterial isolates were isolated belonging to three different genera with their percentage prevalence; Escherichia coli (58.82\%) Salmonella spp (29.41\%), and Shigella spp $(11.77 \%)$ (Table 1). Escherichia coli was the most frequently isolated organism from the stool samples of diarrheic patients. This was consistent with the study conducted by Nas et al. (2017) on enteric bacterial pathogens isolated from diarheic stool samples of patients attending Muritala Muhammad Specialist Hospital, Kano, Nigeria. Their results showed that the most frequently encountered pathogen was Escherichia coli (22\%), followed by Salmonella spp (19\%), Shigella spp (19\%), Klebsiella spp (14\%), Citrobacter spp (14\%) and Pseudomonas aeruginosa (12\%). Similarly, this finding was in agreement with the study conducted by Kim et al. (2015) on enteric bacteria isolated from diarrheic patients in Korea which revealed that Escherichia coli was the most prevalent isolated organism with $22 \%$ while Salmonella spp and Shigella spp had the prevalence of $13.5 \%$ and $0.37 \%$ respectively. The work carried out by Ugwu et al. (2017) in South-Eastern Nigeria, revealed Escherichia coli and Salmonella spp as highly prevalent bacteria isolated in diarrheic stool samples. The high prevalence of Escherichia coli may be due to the fact that it is the predominant facultative flora of the 
human intestine and it is easy to identify to the species level. This is in agreement with the statement by Nataro and Kaper (1998).

The common route of infection by these pathogens is through ingestion of food and drinks contaminated by faeces. Studies have shown that up to $70 \%$ of diarrheal episode are actually caused by water and food contaminated with pathogens (Motarjemi et al., 1993). Similarly, Curtis et al. (2000) stated that there is an association between food vending practices and transmission of enteric bacterial pathogens. In addition, previous study by researchers also reported that variables like age of the child, quality and quantity of water, availability of toilet facilities, housing conditions, level of maternal education, household economic status etc., affect the exposure to diarrheal pathogens and infections (Kwasi and Markku, 2005).

The results of antibiotics sensitivity test showed a high (100\%) resistance to amoxicillin, $70.59 \%$ resistance to streptomycin, $41.18 \%$ resistance to nalixidic acid and least (17.65\%) resistance to imipenem (Table 2). This agrees with other findings which also reported a high $(88.9 \%$ and $90 \%)$ resistance to Amoxicillin (Langendorf et al., 2015; Alemayehu and Mulissa, 2018). The resistance to these antibiotics may be attributed to the production of beta-lactamase, an enzyme that inactivates $\beta$-lactam rings in $\beta$-lactam antibiotics. Also, the high multiple drug resistance $(71.42 \%)$ occurrence exhibited by Escherichia coli is quite alarming (Table 3 ). This suggests high level of exposure to antibiotics which may result due to inappropriate or misuse of antibiotics in both community and hospital settings. The observed multidrug resistance among the enteric bacteria was not peculiar to this study alone. Previous studies have also reported high rate of multidrug resistant (MDR) phenotype among these organisms (Ugwu et al., 2017; Alemayehu and Mulissa, 2018).

\section{CONCLUSION}

This study revealed that the enteric bacteria commonly implicated in the diarrheic stool samples are multi-drug resistant and the most common antibiotics are not effective against them. Based on this finding, there should be continuous surveillance on the prevalence, antimicrobial resistance profiles and plasmid analysis of the genes associated with the bacterial isolates. Also, intervention measures such as intensive health education, provision of safe drinking water, improvement on environmental and personal hygiene and proper use of antibiotics should be done on a regular basis.

\section{REFERENCES}

Ajoke, A. O., Solayide, A. A., Francisca, O. N., Mary-Theresa, N. and Akintoye, O. C. (2012). Cholera Epidemiology in Nigeria: an overview, Pan African Medical Journal, 12:59.

Alemayehu, T. and Mulissa, J. (2018). Prevalence and Antibiotics Susceptibility Pattern ofSalmonella and Shigella species among Diarrhoeal Patients Attending Nekemte Referral Hopsital, Oromia, Ethopia. International Journal of Microbiology, 5:1-6.
Center for Disease Control and Prevention (CDC) (2009). Preliminary Food Net data on the incidence of infection with pathogens transmitted commonly through food-10 states, 2008. Morbidity and Mortality Weekly Report, 58:333-337.

Cheesbrough, M. (2006). Medical Laboratory Manual for Tropical Countries, 2nd edition pp. 138, Cambridge Press, United Kingdom.

Clinical and Laboratory Standards Institute (2019). Performance Standards for AntimicrobialSusceptibility Testing, M100S, 29thedition.

Curtis, V., Cairncross, S., and Yonli, R. (2000). Domestic hygiene and diarrhoea-pinpointing the problem. Tropical Medicine and International Health, 5(1):22-32.

DuPont, H. L. (2014). Acute Infectious Diarrhea in Immunocompetent Adults. The New England Journal of Medicine. 370: 1532-1540.

Ikram-ul-Haq, J. and Muktar, H. (2016). Biosynthesis of protease from Lactobacillus paracasei:

kinetic analysis of fermentation parameters. Indian Journal of $B$ iochemistry and Bio-physics 43:377-381.

Kahali, S., Sarkar, B., Rajendran, K., Khanam, J., Yamasaki, S., Nandy, R. K., Bhattacharya, S. K. and Ramamurthy, T. (2004). Virulence characteristics and molecular epidemiology of enteroaggregative Escherichia coli isolates from hospitalized diarrheal patients in Kolkata India, Journal of Clinical Microbiology, 42 (9):4111-4120.

Kaler, S. G. (2008). Diseases of poverty with high mortality in infants and children: Malaria, measles, lower respiratory infections, and diarrheal illnesses. Annals of the New York Academy of Sciences, 1136: 28-31.

Kim, N., Jung, S., Na, H., Chung, G. T., Yoo, C. K., Seong, W. K., and Hong, S. (2015). Enteric bacteria isolated from diarrhoeal patients in Korea in 2014. Osong Public Health and Research Perspectives, 6(4): 233-240.

Kolader, M. E., Vinh, H., Tuyet, P. T. N., Thompson, C., Wolbers, M. and Merson L. et al. (2013). An oral preparation of Lactobacillus acidophilus for the treatment of uncomplicated acute watery diarrhoea in Vietnamese children: study protocol for a multi-center, randomized, placebo-controlled trial. Trials, $14: 27$.

Kosek, M., Bern, C. and Guerrant, R. L. (2003). The global burden of diarrhoeal disease as estimated from studies published between 1992 and 2000. Bulletin of World Health Organization, 81:197-204.

Kwasi, O. B. and Markku, K. (2005). Childhood diarrheal morbidity in the Accra Metropolitan Area, Ghana: socioeconomic, environmental and behavioral risk determinants. Journal of Health Population in Developing Countries, 1:11. 
Langendorf, C., Le Hello, S., Moumouni, A. Gouali, M. and Mamaty, A. A. et al. (2015). Enteric Bacterial Pathogens in Children with Diarrhoea in Niger: Diversity and Antimicrobial Resistance, PLoS One, 10: 1-18.

Mandomando, I. M., Macete, E. V., Ruiz, J., Sanz, S., Abacassamo, F., Valles, X., Sacarlal, J., Navia, M. M., Vila, J., Alonso, P. L. and Gascon, J. (2007). Etiology of diarrhoea in children younger than 5 years of age admitted in a rural hospital Southern Mozambique. American Journal of Tropical Medicine and Hygiene, 76:522-527.

Mensah, P., Yeboah-Manu, D., Owusu-Darko, K., and Ablordey, A. (2002). "Street foods in Accra, Ghana: how safe are they?" Bulletin of the World Health Organization. 80(7): $546-554$

Meyrowitsch, D. W. and Bygberg, I. B. C. (2007). Global burden of disease- a race against time. Daniel Medical Bulletin, 54:32-34

Motarjemi, Y., Kaferstein, F., Moy, G., and Quevedo, F. (1993). Contaminated weaning food: a major risk factor for diarrhoea and associated malnutrition. Bulletin of the World Health Organization, 71(1): 79.
Nas, F., Ali, M. and Yahaya, A. (2017). Identification of Some Enteric Bacteria from Diarrhoeic Stool Samples of Patients attending Muritala Muhammad Specialist Hospital, Kano, Nigeria. International Journal of Advanced Academic Research, 3:9.

Nataro, J. P. and Kaper, J. B. (1998). Diarrheagenic Escherichia coli. Clinical Microbiology Reviews, 11(1):142-201.

Ugwu, M. C., Edeani, G. I., Ejikeugwu, C. P., Okezie, U. and Ejiofor, S. O. (2017). Antibiotic Susceptibility Profile of Escherichia coli and Salmonella causing Childhood Diarrhoea in Awka Municipality South-eastern Nigeria, Clinical Microbiology, Open Access, 6:2.

World Health Organization (WHO) (2011). WHO Country of Viet Nam health profile.

World Health Organization (2012). WHO Press; World Health Statistics. Geneva, Switzerland. 